\title{
P-M hybrid dysgenesis using geographically separate $P$ strains of Drosophila melanogaster
}

\author{
John F. Y. Brookfield \\ and Sally F. Mitchell
}

Department of Genetics, University of Leicester, University Road, Leicester LE1 7RH

The similarity or otherwise of the mutation spectra generated by different $P$ strains in $P$-M hybrid dysgenesis is of considerable theoretical and practical importance. We report here that the mutations generated on the $X$-chromosome by different $P$ strains, II 2 and Loua 83, are indistinguishable both in quantity and in quality.

\section{INTRODUCTION}

P-M hybrid dysgenesis is a syndrome of abnormalities observed in the F1 of crosses between males of strains carrying a transposable genetic element, the P-factor (P-strains); and females from strains which lack this element (M-strains). The abnormalities include sterility at high temperatures, male recombination and an increased mutation rate (Bregliano and Kidwell, 1983). The mutations observed usually result from the insertion of P-factors (or their smaller, deleted products P-elements) into or near structural genes (Engels, 1983). Some genes are particularly mutable in hybrid dysgenesis, notably the sex-linked singed $(s n)$ locus (Green, 1977). Different P-strains have P-factors situated at different chromosomal locations (Engels, 1983). If the positions of new Pfactor sites generated by transposition depend upon the positions of donor P-factor sequences then positional variation between strains would be expected to result in different mutation spectra. This is potentially important, as insertional mutagenesis with P-elements is now important in cloning Drosophila genes by isolating mutated genes through homology to their inserted sequences (e.g., Searles et al., 1982). However, some genes appear not to be susceptible to $P$ sequence insertions. If this result was a consequence of the $P$ strain used in the dysgenic cross, cloning of such genes might yet be possible using an exotic P-strain as a $\mathrm{P}$ sequence donor.

\section{MATERIAL AND METHODS}

Here we test the hypothesis that different P-strains create different mutation spectra on the $\mathrm{X}$ chromosome. The strains used were $\Pi 2$ (a strong P-strain from Wisconsin (Engels and Preston, 1979)), Loua 83 (a strong P-strain, as measured by the high temperature induction of gonadal dysgenesis, collected recently in Central Africa (Anxolabéhère et al., 1984)), Canton-S (a long-established laboratory M-strain and C(1) DX, $y f: \mathrm{CS}$ (an attached -X yellow forked stock with the Canton $\mathrm{S}$ genetic background). The following crosses were carried out, each at $22^{\circ} \mathrm{C}$.

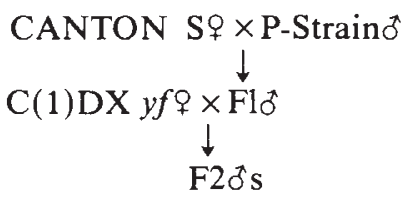

(Examined for visible mutations)

The F2o's thus would carry visible mutants if $P$ elements had been inserted into or near major genes in the $\mathrm{X}$ chromosomes of the germ cells of F1ơs. Loua 83 and $\Pi 2$ were used as paternal Pstrains in separate experiments, and the F2s examined over a 4 week period, during which two generations (referred to below as F2 and F3) emerged. 


\section{RESULTS}

Visible mutations were detected at only two loci; singed (with 31 mutations) and scalloped ( $s d$ )

Table 1

\begin{tabular}{lllrl}
\hline Strain & Generation & Wild type $\delta s$ & $s n \delta s$ & $s d \delta s$ \\
\hline LOUA83 & F2 & 3339 & 7 & 1 \\
$\pi 2$ & F3 & 2431 & 1 & 0 \\
& F2 & 6829 & 16 & 2 \\
& F3 & 4841 & 7 & 0 \\
\hline
\end{tabular}

(with three mutations). (table 1) $\chi^{2}$-tests were carried out to compare the two P-strains for their mutation rates at singed. The results were:

F2: Loua $83 \vee \Pi 2 \quad \chi^{2}=0.060$ Not significant F3: Loua $83 \vee \Pi 2 \quad \chi^{2}=1.589$ Not significant F2 + F3 Loua 83 v $112 \chi^{2}=0.750$ Not significant Loua 83 F2 v F3 $\quad \chi^{2}=2.699$ Not significant $\Pi 2 \mathrm{~F} 2$ v F3 $\chi^{2}=1.128$ Not significant Loua $83+$ II 2 F2 v F3 $\chi^{2}=3.309$ Not significant.

The overall rate of mutation from wild-type to singed was about 1 in 600 chromosomes. This is lower, (though not significantly) than the rates observed in a similar study by Simmons et al. (1984) using both $\Pi 2$ and the Q strain $\nu_{6}$ as Pelement donors. In their experiment the initial cross was to an attached - $\mathrm{X}$ strain, so the mutations subsequently observed were in the P-strain $X$ chromosome and not that of the $M$ strain. This explains their finding of many beadex mutations when using $\Pi 2$, due to chromosome breaks arising at the P-element adjacent to Beadex in the $I 12$
$\mathrm{X}$-chromosome. There is evidence in our data for the clustering of mutations indicating that the mutations occur premeiotically and are shared by groups of flies from the same parents. The snots in the $\mathrm{F} 2 \Pi 2$ data include six which consist of two sets of three brothers, and two of the Loua $83 s n \delta$ s in the F2 could also have been brothers. Thus there may have been, in the data set, only 26 independent sn mutations, not 31 .

Many of the $s n$ mutations generated in this study have been maintained for up to 15 generations, either as males in a stock with attached -X females (as some of these mutations appear to be female-sterile) or as strains in which both males and females possess the mutation. The mutations frequently prove to be unstable in these stocks, reverting either to wild-type or to a weaker singed phenotype (table 2). The revertants are dominant over the singed alleles from which they are derived. Differences between stocks in their reversion rates may be due to differences between the $s n$ mutations in their intrinsic reversion rates and also possibly to differences between stocks in cytotype.

These data, albeit limited, appear to indicate that the mutation spectrum of X-chromosomal insertion mutations in P-M hybrid dysgenesis is insensitive to the $\mathrm{P}$ strain used. Mutationally refractory loci are hence likely to remain so whichever cross is attempted.

Acknowledgments We thank M. Ashburner, M. Shelton, D. Anxolabéhère, G. Périquet, B. Burnet and R. Semeonoff for stocks used in this experiment, R. Semeonoff for the use of laboratory facilities, and an unknown referee for useful comments on the manuscript.

Table 2

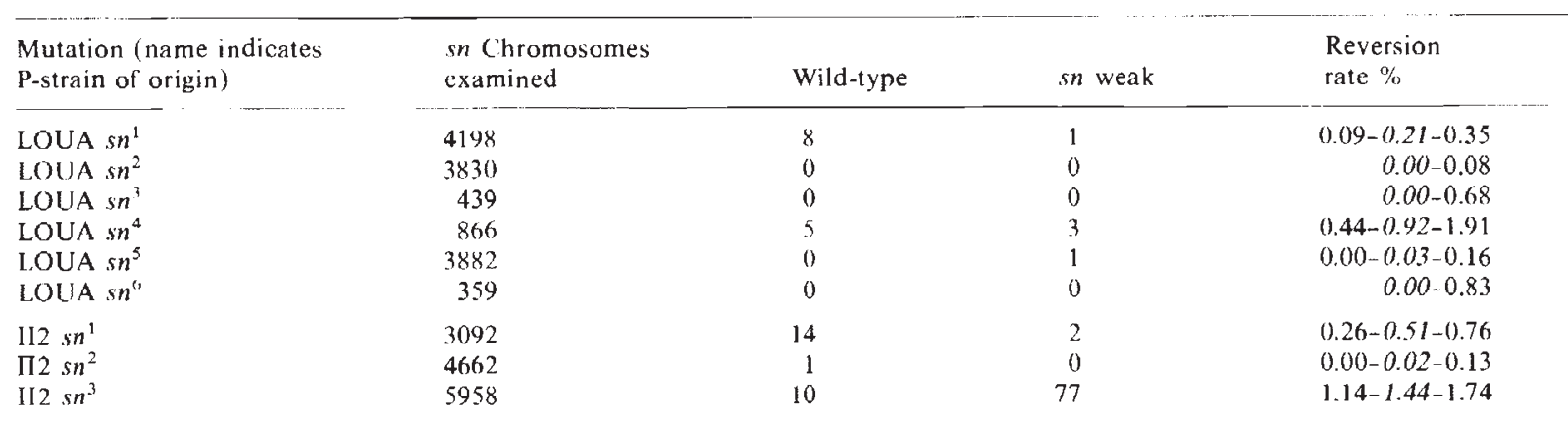

The numbers preceding and following the reversion rate estimates (which are based upon the sums of wild-type and $s n^{w}$ ) are 95 per cent confidence limits based upon the binomial standard error of a proportion or upon the limits of the expectation of this distribution (Fisher and Yates 1963). They are unrealistically close to the rate estimate as they assume falsely that every fly showing a revertant phenotype represents an independent reversion event. 


\section{REFERENCES}

ANXolabéhère, D., hu Kai nouaud, D., PÉRIQuet, G. AND RONSSERAY, S. 1984. The geographical distribution of P-M hybrid dysgenesis in Drosophila melanogaster. Génét. Sel. Évol., 16, 15-26.

BREGLIANO, J. C. AND KIDWELl, M. G. 1983. Hybrid dysgenesis determinants. pp 363-410 in Mobile Genetic Elements. Ed. J. A. Shapiro. Academic Press. London, New York.

ENGELS, W. R. 1983. The P family of transposable elements in Drosophila. Ann. Rev. Genet., 17, 315-344.

ENGELS, W. R. AND PRESTON, C. R. 1979. Hybrid dysgenesis of Drosophila melanogaster: the biology of female and male sterility. Genetics, 92, 161-174.
FISHER, R. A. AND YATES, F. 1963. Statistical tables for biological, agricultural and medical research. 6th Edition. Oliver and Boyd. London.

GREEN, M. M. 1977. Genetic instability of Drosophila melanogaster: de novo induction of putative insertion mutations. Proc. Natl. Acad. Sci. U.S.A., 74, 3490-3493.

SEARLES, L. L., JOKERST, R. S., BINGHAM, P. M., VOELKER, R. A. AND GREENLEAF, A. L. 1982. Molecular cloning of sequences from a Drosophila RNA Polymerase II locus by $\mathrm{P}$ element transposon tagging. Cell, 31, 585-592.

SIMMONS, M. L., RAYMOND, J. D., JOHNSON, N. A. AND FAHEY, T. M. 1984. A comparison of mutation rates for specific loci and chromosome regions in dysgenic hybrid males of Drosophila melanogaster. Genetics, 106, 85-94. 